\title{
Supportive treatment using a compression garment vest of painful sternal instability following deep surgical wound infection: a case report
}

\author{
Andreas Klement ${ }^{1 *}$, Manfred Herrmann ${ }^{2}$
}

\begin{abstract}
Introduction: Sternal dehiscence and instability poses a significant cause of persistent pain and limited quality of life following hospital discharge for $0.2 \%$ to $5 \%$ of patients who have undergone median sternotomy for open heart surgery. We report a successful, conservative, supportive long-term therapy of painful sternal non-union using a customized compression garment vest.

Case presentation: We report a case of painful sternal instability following open heart surgery in a 74-year-old Caucasian man. The complicating factors of obesity (body mass index of 40), renal failure, insulin-dependent diabetes mellitus and absolute arrhythmia with atrial fibrillation were present.

Conclusion: A number of studies have demonstrated the efficacy of surgical interventions for secondary sternal stabilization, but individual patients may reject this option or may be, for other reasons, no longer operable. The task of primary care physicians and other health care providers is to offer this group of patients an alternative option for pragmatic, inexpensive and effective supportive therapy, of which compression garments are an example.
\end{abstract}

\section{Introduction}

Deep surgical wound infections (DSWIs) after coronary artery bypass grafting (CABG) are known to be rare but serious complications. Sternal dehiscence occurs in $0.2 \%$ to $5 \%$ of patients who have undergone median sternotomy, and poses a significant cause of persistent pain and limited quality of life following hospital discharge [1]. Although diverse studies have demonstrated the efficacy of surgical interventions for secondary sternal stabilization, individual patients reject this option or are for other reasons no longer operable [2]. The task of primary care clinicians is to offer this group of patients an alternative option for pragmatic and cost-effective conservative therapy.

\footnotetext{
* Correspondence: andreas.klement@medizin.uni-halle.de ${ }^{1}$ Institute of General Practice, Martin-Luther-University Halle-Wittenberg, Magdeburger Str. 18, D-06112 Halle, Germany

Full list of author information is available at the end of the article
}

\section{Case presentation}

We report a case of painful sternal instability following combined open aortic valve replacement and CABG in a 74-year-old Caucasian man. Alongside the surgically treated aortic valve stenosis (grade III) and two-vessel coronary disease, the complicating factors of insulindependent diabetes mellitus, obesity (body mass index (BMI) of 40), chronic renal insufficiency, and absolute arrhythmia with atrial fibrillation were present. Due to DSWI with confirmation of massive-scale Staphylococcus epidermidis infiltration, wound revision, necrectomy, and vacuum-assisted closure (VAC) were necessary. Ultimately after three weeks of VAC, secondary closure of the thorax could be performed. Considerable wound pain associated with breathing, palpable sternal instability, and local indications of inflammation persisted in our patient for a further three months. A computed tomography (CT) scan of the thorax conducted in response showed sternal non-union up to six mm wide, an old, organizing hematoma closely surrounding the 


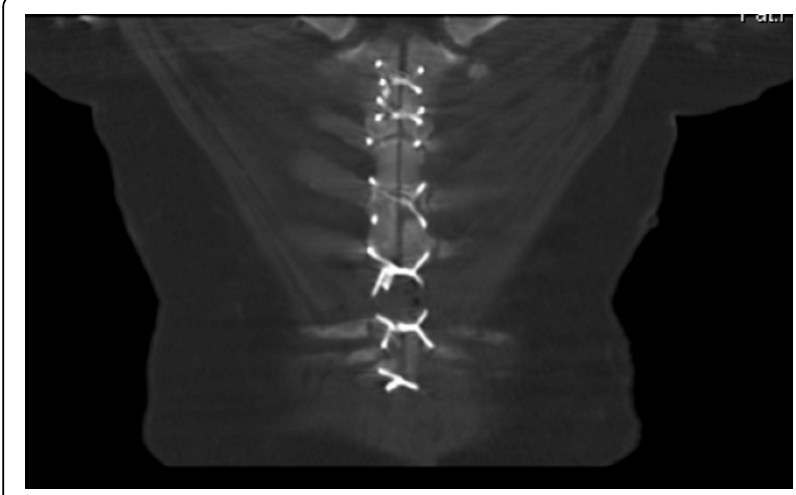

Figure 1 A computed tomography (CT) scan prior to supportive therapy showing sternal non-union (two months after operative refixation).

sternum in a cloak-like manner with a width up to 25 $\mathrm{mm}$, and intact wire stitches (Figure 1). He rejected a repeat surgical wound revision.

We decided in agreement with our patient at his general practitioner's practice to attempt a conservative supportive therapy with an external thoracic support in the form of a customized elastic vest of viscose polyester flat knitwear, with a compression pressure of approximately 20 to $30 \mathrm{mmHg}$ (2.6 to $4 \mathrm{kPa}$ ) (Figure 2). Such 'compression garments' have been used for more than 10 years for compression treatment of hypertrophic scarring [3]. Subsequently, the subjective pain intensity decreased within four weeks from a score of eight to

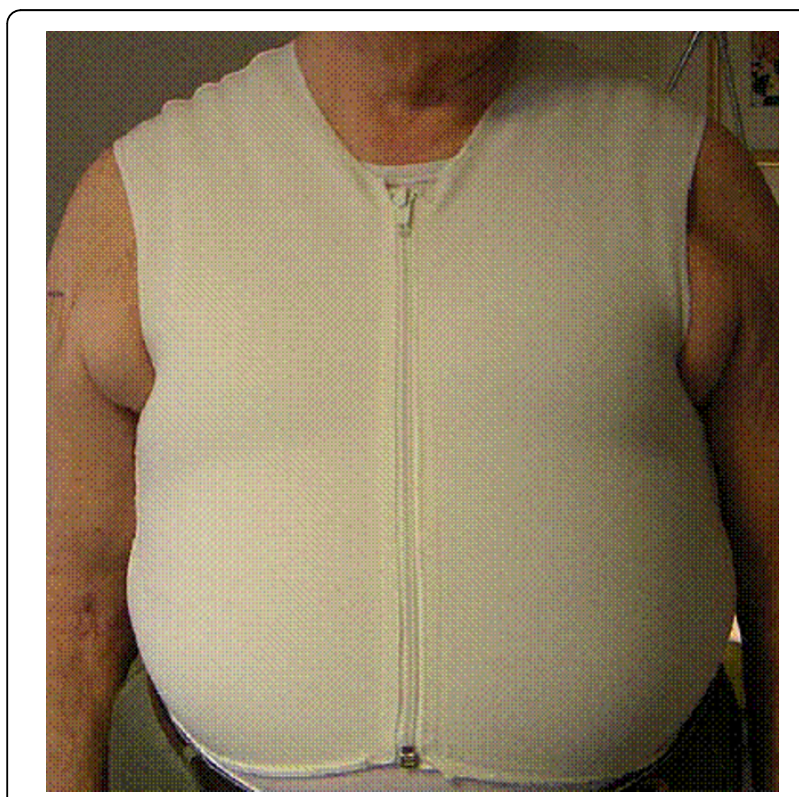

Figure 2 Customized compression garment vest on our 74year-old patient with a body mass index (BMI) of 40 . He experienced painful sternal non-union following median sternotomy.

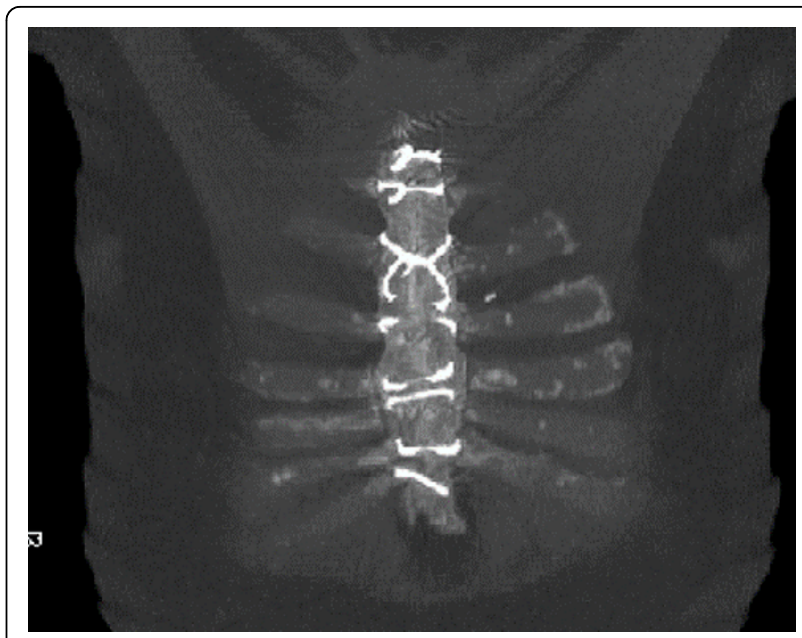

Figure 3 Coronal computed tomography (CT) scan demonstrating the complete osseous wound healing following three months of wearing a compression garment vest ( 7 months after operative refixation).

nine down to two to three on a visual analog scale of 10 points $(100 \mathrm{~mm})$; the need for opioid analgesics was reduced from transdermal fentanyl $100 \mu \mathrm{g}$ /hour every 72 hours to $12.5 \mu \mathrm{g} /$ hour every 72 hours. Due to its multi-directional elastic characteristics (approximately $5 \mathrm{~N} / 15 \%$ fabric stretching), the garment proved itself to be well tolerated even when worn full time under typical everyday conditions. The sternum showed palpatory stability following conservative treatment for three months in total; external scarring was unremarkable. A final CT scan documented completed osseous wound healing and irritation-free connective tissue (Figure 3).

\section{Conclusion}

Devices for external compression of the thorax to prevent or treat sternal instabilities have been systematically investigated in only a few studies, but have shown promising results [4]. Relatively rigid 'corset-like' constructions can, as we have occasionally observed, easily slip out of place, particularly on patients who are obese, and cause skin irritations at the edges of the material due to bulging skin. An alternative is offered by compression garments: they are available worldwide from different manufacturers and in a variety of materials, are relatively inexpensive, and suitable for practical daily use due to their elasticity. In a pilot study involving 15 patients, they were found to be not significantly inferior to rigid 'adjustable fastening braces' in their adaptive effects on sternal wound edges. Long-term comparisons of safety and efficacy in larger study populations have not yet been conducted [5]. To the best of our knowledge, there has been no report to date on conservative supportive long-term therapy of painful sternal nonunion using compression garments. 


\section{Consent}

Written informed consent was obtained from the patient for publication of this case report and any accompanying images. A copy of the written consent is available for review by the Editor-in-Chief of this journal.

\section{Author details}

${ }^{1}$ Institute of General Practice, Martin-Luther-University Halle-Wittenberg, Magdeburger Str. 18, D-06112 Halle, Germany. ${ }^{2}$ Department of Cardiac and Thoracic Surgery, University Hospital Halle, Ernst Grube Str. 40, D-06120 Halle, Germany.

\section{Authors' contributions}

$\mathrm{MH}$ analyzed and interpreted patient data regarding the cardiac and thoracic condition of our patient and the reasons for persisting pain. AK conducted the continuous primary health care, tailoring of the pragmatic supportive therapy and follow-up of our patient, and was a major contributor in writing the manuscript. All authors read and approved the final manuscript.

\section{Competing interests}

The authors declare that they have no competing interests.

Received: 22 September 2009 Accepted: 11 August 2010

Published: 11 August 2010

\section{References}

1. Olbrecht VA, Barreiro CJ, Bonde PN, Williams JA, Baumgartner WA, Gott VL, Conte JV: Clinical outcomes of noninfectious sternal dehiscence after median sternotomy. Ann Thorac Surg 2006, 82:902-907.

2. Sjögren J, Malmsjö M, Gustafsson R, Ingemansson R: Poststernotomy mediastinitis: a review of conventional surgical treatments, vacuumassisted closure therapy and presentation of the Lund University Hospital mediastinitis algorithm. Eur J Cardiothorac Surg 2006, 30:898-905.

3. Van den Kerckhove E, Stappaerts K, Fieuws S, Laperre J, Massage P, Flour M, Boeckx W: The assessment of erythema and thickness on burn related scars during pressure garment therapy as a preventive measure for hypertrophic scarring. Burns 2005, 31:696-702.

4. Gorlitzer M, Folkmann S, Meinhart J, Poslussny P, Thalmann M, Weiss G, Bijak M, Grabenwoeger M: A newly designed thorax support vest prevents sternum instability after median sternotomy. Eur I Cardiothorac Surg 2009, 36:335-339.

5. El-Ansary D, Waddington $G$, Adams R: Control of separation in sternal instability by supportive devices: a comparison of an adjustable fastening brace, compression garment, and sports tape. Arch Phys Med Rehabil 2008, 89:1775-1781.

\section{doi:10.1186/1752-1947-4-266}

Cite this article as: Klement and Herrmann: Supportive treatment using a compression garment vest of painful sternal instability following deep surgical wound infection: a case report. Journal of Medical Case Reports 2010 4:266.

\section{Submit your next manuscript to BioMed Central and take full advantage of:}

- Convenient online submission

- Thorough peer review

- No space constraints or color figure charges

- Immediate publication on acceptance

- Inclusion in PubMed, CAS, Scopus and Google Scholar

- Research which is freely available for redistribution

Submit your manuscript at www.biomedcentral.com/submit
Biomed Central 